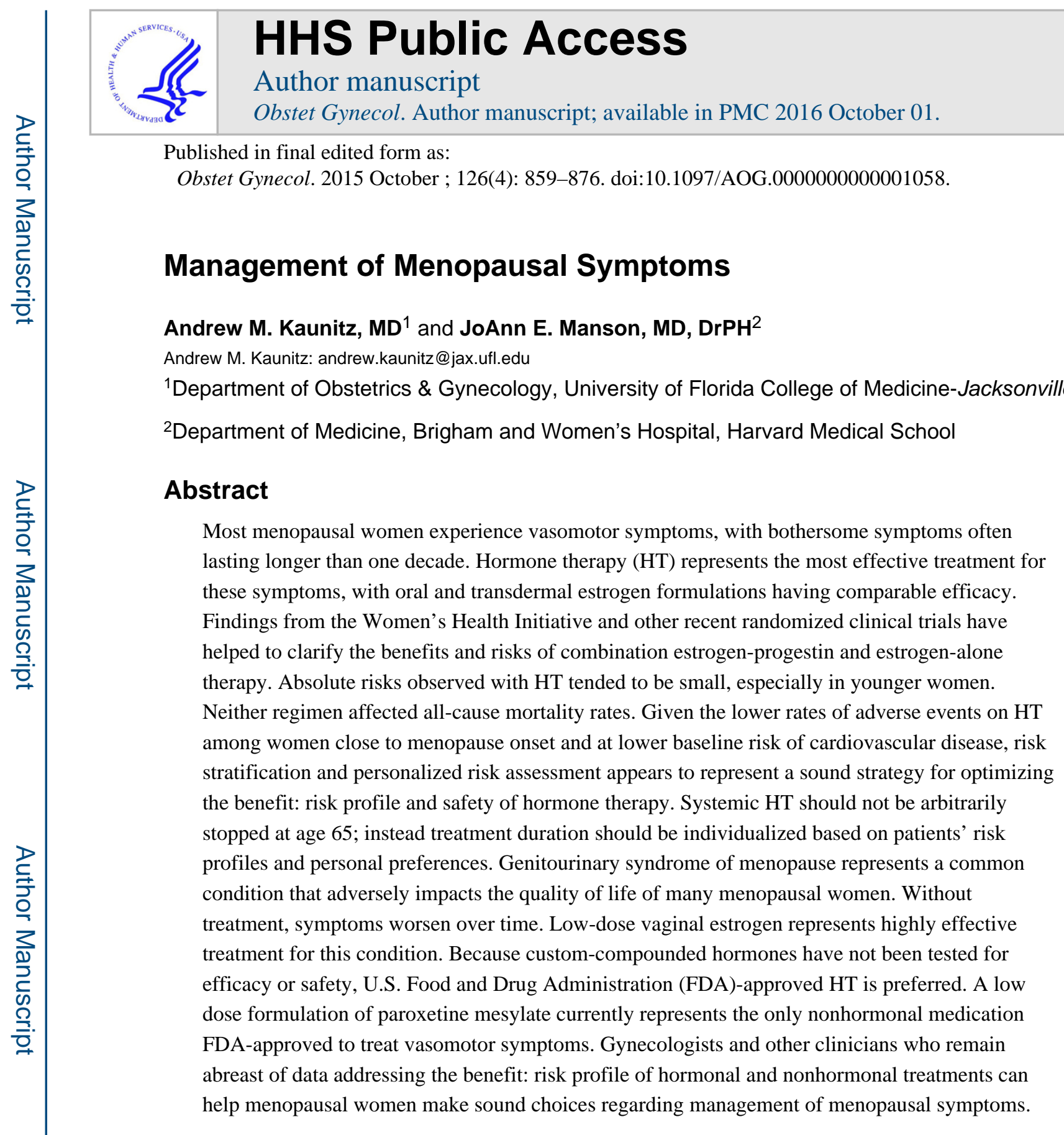

\title{
INTRODUCTION
}

\begin{abstract}
Although menopausal symptoms may impair quality of life, safety concerns have made some clinicians reluctant to initiate or continue treatment. This review updates obstetriciangynecologists and other clinicians regarding hormonal and nonhormonal management of vasomotor symptoms, as well as the management of genitourinary syndrome of menopause.
\end{abstract}

Financial Disclosure:

Dr. Manson did not report any potential conflicts of interest. 


\section{DEMOGRAPHIC OF MENOPAUSE}

Spontaneous menopause, the permanent cessation of menstruation caused by loss of ovarian function, occurs at a mean age of 51-52 years. ${ }^{1}$ As life expectancy increases, women are living far longer after menopause onset than in the past. By 2020, it is projected that more than 50 million U.S. women will be older than 51 years. $^{2}$

\section{VASOMOTOR SYMPTOMS}

Vasomotor symptoms represent the most bothersome symptoms of menopause and the most common reason women seek medical care at the time of the menopausal transition ${ }^{3}$. Often described by women as hot flushes or night sweats, vasomotor symptoms are associated with a sudden sensation of heat in the face, neck, and chest and persist for several minutes or less. Vasomotor symptoms may include flushing, chills, anxiety, sleep disruption, and palpitations. During a hot flush, skin temperature rises due to peripheral vasodilation, particularly in the fingers and toes. Along with peripheral vasodilation and sweating, heart rate increases of $7-15$ beats per minute occur. It may take 30 minutes or longer for the skin temperature to return to baseline. ${ }^{2}$

The pathophysiology of vasomotor symptoms remains poorly characterized. However, these symptoms are known to be caused by estrogen withdrawal, result in a drop in core body temperature ${ }^{4}$ and are linked with pulsatile pituitary luteinizing hormone secretion as well as decreased endorphin concentrations in the hypothalamus. Vasomotor symptoms are associated with an increased release of norepinephrine, serotonin, and other neuroregulators. These neurotransmitters lower a set point in the hypothalamic thermoregulatory nucleus, triggering inappropriate heat loss. ${ }^{5,6}$

The large prospective cohort Study of Women's Health Across the Nation found that vasomotor symptoms are most likely to be reported by women during the late perimenopausal transition (overall prevalence approximately 70\%), and are more prevalent among African American women, those with higher BMIs, less education, lower income, mood disorders, and women who are cigarette smokers. ${ }^{7}$ Surgical or induced menopause is associated with a greater prevalence and severity of vasomotor symptoms. The prevalence of reported vasomotor symptoms varies substantially among women from different cultures; for instance, Asian women are less likely to report such symptoms. ${ }^{8}$ This observation may reflect reporting bias related to cultural norms regarding what is acceptable to report. ${ }^{9}$

\section{Duration of Vasomotor Symptoms}

Understanding the duration of bothersome vasomotor symptoms informs clinical management. The population-based prospective Penn Ovarian Aging Study enrolled older reproductive age women with regular menstrual cycles and followed them over 16 years. The mean age of participants was 42.2 years at baseline and 51.5 years at the time of the final menstrual period. A key finding was that the median duration of hot flushes reported by women to be moderate-to-severe was 10.2 years. Among women whose symptoms began around the time of onset of the perimenopausal transition, the median duration of symptoms was 11.6 years. Similar to the Study of Women's Health Across the Nation report, the Penn 
Ovarian Aging Study found that the prevalence of vasomotor symptoms was greater among African American and obese women. ${ }^{1,10}$

\section{Behavioral Treatment of Vasomotor Symptoms}

Common sense measures to address vasomotor symptoms include portable fans, lowering the ambient temperature, wearing layered clothing, avoiding tobacco, alcohol, caffeine, and spicy foods as well as ingesting cool drinks. ${ }^{11}$ An RCT of 187 symptomatic menopausal women found that clinical hypnosis was associated with a $74.2 \%$ reduction in hot flushes, compared with a $17.1 \%$ reduction in women randomized to structured attention control $(\mathrm{P}<$ 0.001). ${ }^{12}$ The effectiveness of acupuncture, ${ }^{13}$ exercise, ${ }^{14}$ yoga, ${ }^{15}$ paced respiration, ${ }^{16}$ relaxation training, ${ }^{17}$ and mindfulness-based stress reduction ${ }^{18}$ has not been established.

\section{Over-the-Counter Products}

Over-the-counter herbal formulations, including soy, black cohosh, and other botanicals have been widely used to treat vasomotor symptoms. In a one-year randomized controlled trial (RCT) of 341 symptomatic perimenopausal or postmenopausal women, these herbal agents were not found to be more effective than placebo while the efficacy of conjugated equine estrogens 0.625 was demonstrated. ${ }^{19}$ A meta-analysis of 30 placebo-controlled trials of phytoestrogens (which include genistein, daidzein, found in soybeans and red clover) concluded that these agents were not effective in treating vasomotor symptoms. ${ }^{20} \mathrm{~A}$ recent randomized trial of omega-3 fatty acid supplements showed no efficacy for vasomotor symptom management. ${ }^{21}$

\section{HORMONAL PRESCRIPTION MEDICATIONS}

\section{Systemic Hormone Therapy}

Numerous RCTs have demonstrated that estrogen represents the most effective treatment for menopausal vasomotor symptoms and related issues including impaired sleep, irritability, and decreased quality of life. ${ }^{22}$ Higher doses are associated with enhanced efficacy. Oral and transdermal estrogen formulations have comparable efficacy in treating menopausal symptoms. ${ }^{23}$ With the exception of the $0.14 \mathrm{mg}$ ultra-low dose estradiol patch , all systemic estrogen formulations are approved for treatment of vasomotor symptoms. ${ }^{22}$

In women with an intact uterus, treatment with estrogen alone is associated with an elevated risk of endometrial neoplasia with dose and duration of treatment directly related to the magnitude of this risk. ${ }^{24}$ When adequate progestogen is combined with estrogen, risk of endometrial neoplasia is not higher than in untreated women. In the Women's Health Initiative clinical trial, at a mean of 5.6 years of follow-up, use of continuous oral conjugated equine estrogens $0.625 \mathrm{mg}$ plus medroxyprogesterone acetate $2.5 \mathrm{mg}$ daily was associated with a risk of endometrial cancer similar to placebo (hazard ratio 0.81 (95\% CI, $0.48-1.36),{ }^{25}$ and risk was significantly reduced after 13 years of cumulative follow-up. ${ }^{26} \mathrm{~A}$ large, long-term Finnish observational study noted that while continuous concomitant progestin therapy is associated with a risk of endometrial neoplasia lower than seen in women not using HT, sequential progestin therapy (eg, 14 days each month) was associated with an elevated risk. Long-cycle progestin therapy (eg, 14 days every 3 months) was 
associated with a further elevation in risk of endometrial cancer. Neither route nor type of progestin appeared to affect the risk of endometrial neoplasia, ${ }^{27}$, although additional research is needed on non-medroxyprogesterone formulations. Based on these observations, combination estrogen-progestin therapy is generally employed when systemic HT is prescribed to women with an intact uterus.

Progestational formulations are also effective in treating vasomotor symptoms, but not as effective as estrogen. ${ }^{28}$ A Cochrane Review found that combination estrogen-progestogen HT is more effective than estrogen alone in treating vasomotor symptoms. ${ }^{29}$ No long term studies address the safety of progestogen-only treatment of menopausal symptoms. Use of progestogen-only therapy to treat vasomotor symptoms is further discussed later (see USE

\section{OF HORMONE THERAPY IN SPECIAL PATIENT POPULATIONS.}

In 2013, a formulation combining $0.45 \mathrm{mg}$ conjugated equine estrogens with the estrogen agonist-antagonist bazedoxifene (20mg) was approved by the FDA for the treatment of vasomotor symptoms and the prevention of osteoporosis among women with an intact uterus. In a 12-month trial, rates of endometrial hyperplasia and amenorrhea among women allocated to this combination formulation were similar to those randomized to placebo. ${ }^{30}$

Although clinical trials of conjugated equine estrogens-bazodoxifene have not suggested that this formulation increases risk of breast cancer, trials have not been large or long enough to adequately assess this association. In contrast with estrogen-progestin therapy, which increases mammographic breast density and breast tenderness, bazodoxifene has not been found to increase breast density or tenderness. ${ }^{31}$

In the United States, the most commonly used oral estrogens for systemic treatment of menopausal symptoms are estradiol and conjugated equine estrogens. Standard doses of oral estradiol and conjugated equine estrogens are $1.0 \mathrm{mg}$ and $0.625 \mathrm{mg}$, respectively. ${ }^{23}$ Higher and lower doses of these formulations are also available.

Transdermal estradiol formulations are also available. Skin patches represent the most commonly used transdermal estradiol formulations. Patches releasing 0.0375 and $0.05 \mathrm{mg}$ estradiol daily are considered standard dose. ${ }^{23}$ Patches with higher and lower doses are also available. Ultra-low dose patches which release $0.025 \mathrm{mg}$ or $0.014 \mathrm{mg}$ estradiol daily are also available. In addition, transdermal estradiol gels, emulsion, and spray are available in a variety of doses. ${ }^{32}$ A 3-month vaginal estradiol-releasing ring can also be used for systemic estrogen therapy (ET): the ring releasing $0.05 \mathrm{mg}$ estradiol daily is considered standard dose.

Although estrogen injections as well as estrogen pellets have been used to treat menopausal symptoms, serum estradiol levels associated with use of these formulations have not been well characterized. Accordingly, use of oral or transdermal estrogen formulations is recommended. Estrogen pellets are not FDA approved (see Custom-Compounded Bioidentical Hormone Therapy).

Common adverse effects of estrogen include breast tenderness, bloating, and uterine bleeding. Although lowering the dose may reduce these adverse effects, this may also result in reduced relief of vasomotor symptoms. Some clinicians encourage menopausal women 
initiating systemic HT to start with a standard dose, while others recommend starting therapy using a lower dose and titrate upward. Either way, it is appropriate to use the lowest effective dose for the shortest period of time that allows the individual patient to achieve her goals. ${ }^{23}$ The indications and contraindications for the use of menopausal hormone therapy and related medications are summarized in Box 1.

Few menopausal women using systemic HT benefit from monitoring serum estrogen levels. However, when postmenopausal patients report inadequate symptom relief despite the use of escalating doses of estrogen, monitoring serum estradiol levels can be useful. Compared with the fluctuating serum levels associated with oral estrogen, the use of transdermal estradiol results in a relatively steady level of serum estradiol and facilitates the monitoring of serum estrogen levels. In general, serum estradiol levels 40 to $100 \mathrm{pg} / \mathrm{mL}$ represent a reasonable target range when monitoring serum estrogen levels in women using transdermal estradiol. Our clinical experience suggests that in young highly symptomatic postmenopausal women, estradiol levels below this range may not result in adequate symptom relief. ${ }^{32}$ Medical and iatrogenic conditions that can cause heat intolerance or the sensation of flushing and can masquerade as hot flushes are listed in Box 2. ${ }^{2}$

In the United States, the progestational agents most commonly prescribed to menopausal women with an intact uterus using systemic HT are medroxyprogesterone acetate (available in $2.5 \mathrm{mg}, 5 \mathrm{mg}$ and $10 \mathrm{mg}$ doses) and micronized progesterone (available in $100 \mathrm{mg}$ and $200 \mathrm{mg}$ doses). Because micronized progesterone is formulated with peanut oil, it should not be used by women with peanut allergies. With standard dose estrogen, an appropriate dose of medroxyprogesterone acetate is $2.5 \mathrm{mg}$ daily for continuous therapy, or $5 \mathrm{mg}$ daily with sequential therapy. An appropriate dose of micronized progesterone is $100 \mathrm{mg}$ daily for continuous therapy or $200 \mathrm{mg}$ nightly for sequential therapy. ${ }^{33}$ Because micronized progesterone at either dose can cause hypnotic effects, this medication should be taken at bedtime.

In some menopausal women, dysphoria may result from use of progestins. ${ }^{22}$ Changing to a different progestin, lowering the progestin dose, prescribing progestin sequentially (including long-cycle), or initiating antidepressant therapy may be useful in such patients. Although off-label, use of a progestin-releasing intrauterine device provides endometrial suppression while exposing the central nervous system to lower levels of progestin than those achieved with oral or transdermal administration. ${ }^{34}$

A number of oral estrogen-progestin formulations are available, combining oral conjugated equine estrogens with medroxyprogesterone, oral estradiol, or ethinyl estradiol with norethindrone acetate, and oral estradiol with norgestimate or drospirenone. Transdermal estrogen-progestin patches combine estradiol with norethindrone acetate or levonorgestrel. To receive FDA approval, combination estrogen-progestin formulations must have demonstrated endometrial safety. Regularly updated tables detailing all U.S. and Canadian formulations approved by regulatory authorities for the treatment of menopausal vasomotor and genitourinary symptoms are available from the North American Menopause Society: (http://www.menopause.org/docs/default-source/2014/nams-ht-tables.pdf). 
Systemic Hormone Therapy Safety-Findings from the Women's Health Initiative (WHI) and other recent randomized clinical trials have helped to clarify the benefits and risks of combination estrogen-progestin and estrogen-alone therapy. A 2013 WHI report included a comprehensive overview of findings from the two HT trials with extended postintervention follow up (median, 13 years of cumulative follow-up) and with results stratified by age. ${ }^{26}$ Importantly, absolute risks of adverse events related to hormone therapy were much lower for younger women (ages 50-59) than for older women, as shown in Figure 1.

Results for chronic disease outcomes in the WHI HT trials are summarized for the overall cohort during the intervention phase and at 13 years of cumulative follow up in Table 1. Although hormone therapy was associated with a complex pattern of benefits and risks in both trials, absolute risks (increase or decrease in number of cases per 10,000 women treated per year) tended to be small. The hazard ratio (HR) for coronary heart disease during the intervention phase was 1.18 (95\% confidence interval [CI] 0.95-1.45) in the conjugated equine estrogens plus medroxyprogesterone acetate trial and $0.94(0.78-1.14)$ in the conjugated equine estrogens-alone trial; neither demonstrate a statistical significance In both trials, women in the treatment arm had reduced risks of vasomotor symptoms, hip fractures, and diabetes, and increased risks of stroke, venous thromboembolism, and gallbladder disease compared to women receiving placebo. Results for breast cancer were divergent in the two trials, with increased risk in the conjugated equine estrogens plus medroxyprogesterone acetate trial and borderline reduced risk in the conjugated equine estrogens-alone trial during the intervention period. Rates of dementia (in women aged 65 years or older) were also increased in the conjugated equine estrogens plus medroxyprogesterone acetate trial, but not in the conjugated equine estrogens-alone trial.

During the poststopping phase, most risks and benefits dissipated, although some elevation in breast cancer risk persisted in the conjugated equine estrogens plus medroxyprogesterone acetate trial (cumulative HR over 13 years $=1.28 ; 95 \%$ confidence interval, 1.11-1.48), while a significantly reduced risk of breast cancer $(\mathrm{HR}=0.79$ [0.65-0.97]) emerged over this time period in the conjugated equine estrogens-alone trial (Table 2). To put the elevated risk of breast cancer observed among women randomized to conjugated equine estrogens plus medroxyprogesterone acetate in perspective, the attributable risk with combination hormone therapy is less than one additional case of breast cancer diagnosed per 1,000 users of combination hormone therapy annually. Regarding risk of breast cancer, another way to put this elevated HR in perspective is to recognize that a hazard ratio of 1.28 is slightly higher than that seen with one daily glass of wine, and less than that noted with two daily glasses. ${ }^{35}$ In the conjugated equine estrogens plus medroxyprogesterone acetate trial, a nonsignificantly elevated risk of ovarian cancer also was identified over 13 years of cumulative follow-up (94 cases; HR 1.24; 95\% CI 0.83-1.87), while statistical power was too low to assess this outcome in the conjugated equine estrogens-alone trial. In general, results for chronic disease outcomes tended to be more favorable for conjugated equine estrogens-alone than for conjugated equine estrogens plus medroxyprogesterone acetate. Neither regimen affected all-cause mortality rates. ${ }^{26}$ 
In addition to lower absolute risks of adverse events on HT in the younger compared with older women, age and time since menopause appeared to influence several of the HRs observed in the trials. In the conjugated equine estrogens-alone trial, women aged 50-59 years had more favorable results for all-cause mortality, myocardial infarction (MI), colorectal cancer, and the global index (nominal $\mathrm{P}$ values for trend by age in the HRs was $<0.05$ for each). In the conjugated equine estrogens plus medroxyprogesterone acetate trial, an elevated risk of MI with treatment was apparent only in women at least a decade past menopause onset. ${ }^{26}$ Both HT regimens, however, were associated with increased risks of stroke, venous thrombosis, and gallbladder disease, with no clear differences in hazard ratios by age for these outcomes. For conjugated equine estrogens plus medroxyprogesterone acetate, an increased risk of breast cancer was an additional adverse effect in all age groups. However, the lower absolute risks of adverse events in younger women (Figure 1), together with the generally more favorable HRs for many outcomes in the younger women, resulted in much lower rates of adverse events attributable to HT in the younger compared with older age groups.

Regarding coronary heart disease, the potential influence of age or time since menopause on the vascular response to HT has received considerable attention. ${ }^{22,36-39}$ It has been postulated that estrogen may slow early stages of atherosclerosis but has plaquedestabilizing and other adverse effects on advanced atherosclerotic lesions. ${ }^{36,39}$ In WHI, the findings that women with elevated LDL-cholesterol concentrations, other dyslipidemias, or metabolic syndrome, but not those without these risk factors, had increased risks of coronary events while using $\mathrm{HT}^{40-43}$ are consistent with this hypothesis. Additional support for the "critical window" hypothesis derives from a randomized trial of women aged younger than 50 years at enrollment, in which 10 years of combination estrogen-progestogen was associated with reduction of a composite endpoint that included cardiovascular disease, ${ }^{44}$ and preliminary findings from the Early versus Late Intervention Trial with Estradiol showing an effect of estrogen in slowing atherosclerosis progression among women in early, but not late, menopause. ${ }^{45}$ However, the former trial was designed to assess osteoporosis and has been criticized for a nonblinded design, a composite outcome that included heart failure, and low statistical power. ${ }^{46}$ Also, a recent primary prevention trial of newly menopausal women (The Kronos Early Estrogen Prevention Study) did not demonstrate a difference in progression of atherosclerosis by noninvasive imaging after four years of therapy. ${ }^{47}$ Thus, the "critical window" hypothesis, although supported by extensive evidence, remains controversial.

Given the lower rates of adverse events on HT among women close to menopause onset and at lower baseline risk of cardiovascular disease, the use of risk stratification (categorizing individuals by their clinical characteristics and risk factor status) and personalized risk assessment has been proposed to improve the benefit: risk profile and safety of HT. One approach to decision-making from the North American Menopause Society is presented in an algorithm in Figure 2 and is available in a free mobile application (app) called MenoPro (dual mode for clinicians and patients, downloadable on iPhone, IPad, and Android devices). ${ }^{48}$ This approach includes assessment of whether the patient has moderate-to-severe menopausal symptoms, incorporation of the patient's preferences regarding hormonal compared with nonhormonal therapy, and evaluation of the presence of contraindications to 
HT, as well as the patient's time since menopause onset and baseline risks of atherosclerotic cardiovascular disease (using an internal risk calculator that incorporates information on the patient's age, smoking status, systolic blood pressure level, antihypertensive therapy, presence or absence of diabetes, and total and HDL cholesterol measurements: available at http://www.imedicalapps.com/2014/04/ascvd-risk-estimator-app/). ${ }^{49}$

The algorithm and app also address the patient's risk of breast cancer, osteoporosis, and other conditions relevant to clinical decision making about HT initiation and duration of treatment. Information about treatment options, including regimens and doses, is also provided.

Use of Estrogen Therapy in Women With Prior Hysterectomy-In the 1990s, more than $90 \%$ of women in their 50s who had undergone hysterectomy used ET. In contrast, subsequent to the initial publication of the Women's Health Initiative findings in 2002 , this proportion has fallen to less than one third. Investigators used modeling to estimate the health effects of the decline in use of ET posthysterectomy, concluding that this decline may have increased mortality in this subgroup of U.S. women. ${ }^{50}$ When counselling symptomatic women in their 50s (or younger) after hysterectomy, clinicians should clarify that for most such women, benefits of ET are likely to outweigh risks.

\section{Systemic Hormone Therapy: Dose Tapering, Discontinuation, and Extended} Duration Use-Although common in clinical practice, extended (eg, more than 5 years) use of systemic HT is controversial as little clinical trial data address this issue. Although some have suggested that systemic HT should not be prescribed for more than 2 or 3 years, given that the mean duration of bothersome symptoms is more than one decade, ${ }^{1}$ this advice will not address the need for symptomatic treatment in many menopausal women.

The following recommendations are drawn from our clinical experience: Several years after initiating treatment using standard dose HT, it is reasonable to encourage the patient to try a lower dose, with the reassurance that should bothersome symptoms occur, she can resume the prior higher dose without having to return for an office visit. This approach can continue until the patient is using a low or ultralow dose of HT (eg, oral estradiol $0.5 \mathrm{mg}$, conjugated equine estrogens $0.3 \mathrm{mg}$, or transdermal estradiol $0.014-0.025 \mathrm{mg}$ ). After remaining free of symptoms on low dose HT, many women may choose to try stopping HT. However, others, particularly those at elevated risk for osteoporosis (eg, lean women and those with a maternal or paternal history of osteoporosis) as well as those who perceive an enhanced overall quality of life with use of systemic HT, may choose to continue low-dose therapy.

In 2012, the American Geriatric Society updated its list of medications that should be used with caution. ${ }^{51}$ This has resulted in physicians prescribing systemic HT to women older than age 65 years receiving notices denying reimbursement for such therapy. The American College of Obstetricians and Gynecologists recommends against arbitrarily discontinuing systemic HT at age 65 , instead encouraging that treatment decisions be '...individualized based on each woman's individual risk-benefit ratio and clinical presentation'. ${ }^{23}$ Although randomized trials have not compared risk of thromboembolic disease with oral vs. transdermal HT formulations, observational studies suggest that the risk of thrombosis is 
lower with transdermal HT, ${ }^{52}$ In addition, in contrast with oral HT, transdermal HT does not appear to increase the risk of thrombosis in women with thrombophilic conditions. 53

Transdermal estrogen formulations represent an appropriate choice for older menopausal women, particularly those who are overweight or obese. Likewise, extended duration use of HT represents a more attractive option when estrogen-only therapy can be employed. ${ }^{54}$

Custom-Compounded Bioidentical Hormone Therapy-Although most often used to describe custom-made HT formulations compounded according to a clinician's prescription, the term biodentical hormone refers to hormones identical to those made by the ovaries. Recently, use of compounded HT has increased among U.S. women, with as many as 2.5 million U.S. women using these formulations, a trend propelled by advocacy from celebrities. ${ }^{55,56}$ More than three quarters of women using compounded HT are not aware these formulations are not evaluated or approved by the FDA. ${ }^{55}$ Prescription of compounded HT often follows salivary hormone testing, which does not reliably assess serum hormone levels. ${ }^{57}$ Most women using compounded hormone therapy are not aware that FDAapproved oral, transdermal, and vaginal estradiol as well as oral progesterone formulations are in fact bioidentical. Because custom-compounded hormones have not been tested for efficacy or safety by the FDA, and standardization and purity is uncertain, the American College of Obstetricians and Gynecologists indicates that FDA-approved HT is preferred.$^{23}$ Occasionally, when a specific FDA-approved formulation is not available, it may be appropriate to prescribe compounded HT.

\section{Use of Estrogen-Only Therapy in Women With an Intact Uterus-Some}

menopausal women with an intact uterus wishing to use systemic HT would like to avoid concomitant use of a progestogen. One option for such women would be use of the formulation combining oral conjugated equine estrogens with bazedoxifene. Another option, rarely employed in the US, is estrogen-only therapy with endometrial surveillance. In a 2year trial, British investigators randomized menopausal women with an intact uterus to an estrogen-only regimen, oral estradiol valerate $2 \mathrm{mg}$ (the equivalent of approximately $1.5 \mathrm{mg}$ of oral micronized estradiol), ${ }^{58}$ or placebo. As with the longer-term Women's Health Initiative trial, the British study found that 2 years of estrogen did not increase risk for breast cancer. 59

Concerns regarding endometrial cancer prevent clinicians from routinely recommending estrogen-only therapy for symptomatic menopausal women with an intact uterus. In the British trial, with 2 years of unopposed ET, and a protocol that employed endometrial biopsy with short-term cyclical progestin treatment in response to any reported bleeding, no increased risk of endometrial cancer was observed. ${ }^{59}$ Other placebo-controlled trials of menopausal women with an intact uterus who received 2-3 years of ET (either estradiol 1 $\mathrm{mg}$ or conjugated equine estrogens $0.625 \mathrm{mg}$ ) observed no cases of endometrial cancer in women randomized to ET. ${ }^{60,61}$ However, the incidence of endometrial hyperplasia is high in women taking unopposed estrogen. In a 3-year trial, the incidence of simple, complex, and atypical hyperplasia was $27.7 \%, 22.7 \%$, and $11.8 \%$, respectively, among women randomized to estrogen-only, while the incidence of each of these types of hyperplasia was $<1 \%$ among those randomized to placebo. ${ }^{60}$ Disadvantages of prescribing estrogen-only 
therapy to women with an intact uterus include uterine bleeding, the need for endometrial surveillance with vaginal ultrasound-endometrial biopsy, and the recognition that some women will likely undergo hysterectomy should hyperplasia with atypia be found. Given these issues and the fact that combination therapy currently represents the standard of care for treatment of symptomatic women with a uterus, ${ }^{23}$ few clinicians and women will choose estrogen-only therapy when a uterus is present. However, some symptomatic women seeking hormonal management may be more concerned about the elevated risk of breast cancer with combination estrogen-progestin therapy than the potential for bleeding or endometrial hyperplasia with estrogen-only therapy. For such women who also decline or are not candidates for conjugated estrogens-bazedoxifene, short-term estrogen-only therapy with appropriate endometrial surveillance represents an appropriate option. Because endometrial cancer can occur in women after endometrial ablation, ${ }^{62}$ estrogen thrapy should be accompanied by progestational endometrial suppression when women use HT after ablation.

Testosterone-Used concomitantly with ET and HT, testosterone does not appear to enhance efficacy of treatment of vasomotor symptoms. ${ }^{63}$ While testosterone can increase sexual desire in menopausal women, ${ }^{64}$ it appears to achieve efficacy only with supraphysiologic doses, which are likely to cause hyperandogenic adverse effects. ${ }^{65}$

\section{NONHORMONAL PRESCRIPTION MEDICATIONS}

Selective serotonin reuptake inhibitors and serotonin-norepinephrine reuptake inhibitors (more commonly used to treat depression) as well as anticonvulsant medications (more commonly used to treat neuropathic pain) are increasingly being used off-label in the nonhormonal management of vasomotor symptoms. In RCTs, paroxetine, escitalopram, citalopram, venlafaxine, desvenlafaxine, gabapentin and pregabalin have been effective in treating vasomotor symptoms. ${ }^{66}$ Low-dose paroxetine mesylate currently represents the only nonhormonal formulation FDA-approved for the treatment of vasomotor symptoms.

The antidepressants best studied in the treatment of vasomotor symptoms agents are paroxetine mesylate and venlafaxine. Lower doses of these agents than those used to treat psychiatric disorders are often effective in treating hot flushes. Although these medications may cause nausea, headache, and dizziness, these side effects are less common than when the same medications are used to treat psychiatric conditions; furthermore, these side effects often subside within several weeks of initiating treatment. In two RCTs (12 and 24 weeks in duration) of 1,184 postmenopausal women, a $7.5 \mathrm{mg}$ formulation of paroxetine was found to be effective in treating vasomotor symptoms. ${ }^{67}$ In contrast with use of higher-dose paroxetine for psychiatric indications, initial dose escalation is not needed with paroxetine $7.5 \mathrm{mg}$; likewise, patients discontinuing this medication do not need to taper off of it.

In an 8-week double-blind RCT of 339 perimenopausal and postmenopausal women, venlafaxine $75 \mathrm{mg}$ extended release and low-dose oral estradiol $(0.5 \mathrm{mg})$ demonstrated similar efficacy in treating vasomotor symptoms, with both agents found to be more effective than placebo. ${ }^{68}$ 
Tamoxifen is a prodrug which must be metabolized by the hepatic enzyme Cyp2d6 to endoxifen to exert its effect as adjuvant therapy in the treatment of receptor-positive breast cancer. Paroxetine and fluoxetine represent potent inhibitors of the hepatic enzyme Cyp2d6 and therefore should not be used by women taking tamoxifen. In contrast, venlafaxine, desvenlafaxine, gabapentin, and pregabalin do not inhibit Cyp2d6 and therefore may be appropriate nonhormonal medications for the treatment of bothersome vasomotor symptoms in women taking tamoxifen. ${ }^{66}$

In RCTs, gabapentin at daily doses ranging from 900-2400 mg has been found more effective than placebo in treating hot flushes. The recommended dose is $900 \mathrm{mg} / \mathrm{d}$ in three divided doses, with a starting dose of $300 \mathrm{mg} / \mathrm{d}$. Likewise, pregabalin (a newer formulation similar to gabapentin) has been found to effectively treat vasomotor symptoms. The recommended dose is $75 \mathrm{mg}$ twice daily, with a starting dose of $50 \mathrm{mg} / \mathrm{d}$. Both of these medications can produce dose-related dizziness and sedation. ${ }^{66}$ Bellergal, clonidine, and methyldopa represent central-acting medications that have demonstrated some efficacy in treating hot flushes in clinical trials. However, since these medications produce substantial side effects, their use in treating hot flshes is in general not recommended unless other treatments are ineffective or poorly tolerated. ${ }^{66}$

Stellate Ganglion Block-Stellate ganglion block has been assessed in the treatment of vasomotor symptoms. A small RCT of 40 postmenopausal women compared the effects of stellate ganglion block with a sham injection. The resulting overall frequency of vasomotor symptoms was similar in the active and sham groups. However, the frequency of moderateto-severe hot flushes as well as that of objectively measured symptoms was reduced significantly more by the active than by the sham treatment. ${ }^{69}$ A larger, sham-controlled RCT of this modality would be appropriate.

\section{GENITOURINARY SYNDROME OF MENOPAUSE}

Although use of systemic HT has dramatically declined since initial 2002 publication of findings from the Women's Health Initiative ${ }^{70}$ some three quarters of U.S. women aged 5774 years are sexually active. ${ }^{71}$ These observations underscore the importance of recognizing and treating genitourinary syndrome of menopause.

Also known as vulvovaginal atrophy, genitourinary syndrome of menopause refers to the physical changes of the vulva, vagina, and lower urinary tract that result from estrogen deficiency and represents a common and progressive condition that adversely affects health, sexuality, and quality of life of many menopausal women. The word "atrophy" may be perceived in a negative fashion by midlife women; likewise, the media and the public may not be comfortable using the term "vagina." Furthermore, vulvovaginal atrophy does not encompass the lower urinary tract. Accordingly, a consensus panel (with representation from the American College of Obstetricians and Gynecologists) was convened in 2013 and recommended "genitourinary syndrome of menopause" as preferred terminology. ${ }^{72}$

Because high concentrations of estrogen-receptor $a$ are present in the vaginal epithelium of premenopausal and postmenopausal women, endogenous estradiol causes the epithelium to become a thick, well-vascularized rugated surface that provides adequate lubrication for 
most premenopausal women. Genitourinary syndrome of menopause results from low systemic estrogen levels which most commonly are associated with spontaneous menopause, but can also occur due to induced menopause or transient low estrogen states including lactation and use of gonadotropin-releasing hormone agonists.

Genitourinary syndrome of menopause may cause the vagina to shorten and narrow, and the introitus may contract, particularly in the absence of penetrative sexual activity. The vaginal epithelium becomes thin and sebaceous gland secretions diminish, causing lubrication from sexual stimulation to be delayed as well as decreased. The term atrophic vaginitis refers to inflammation that occurs with this syndrome. ${ }^{73}$

Although approximately one third of midlife and older women report dryness and pain with intercourse, only a minority seek help for genitourinary syndrome of menopause. In contrast with vasomotor symptoms, genitourinary syndrome of menopause often progresses without treatment. Because many women with this condition may not report symptoms, clinicians should enquire about symptoms, including vaginal dryness and sexual discomfort, during well-women visits.

Genitourinary syndrome of menopause can be presumptively diagnosed based on a characteristic history alone. However, performing a pelvic examination helps exclude other vulvovaginal conditions that may present with similar symptoms, including chronic infections, contact dermatitis, lichen sclerosus, lichen planus, and malignancy. During inspection of the external genitalia, the clinician may note loss of the fat pad in the mons and labia majora as well as loss of labia minora tissue and pigmentation. The urethral meatus may become erythematous and prominent. If introital or vaginal narrowing is present, use of an ultrathin speculum minimizes patient discomfort. The vaginal epithelium may appear smooth (loss of rugation), shiny, and dry. Use of a spatula or cotton-tip swab may cause bleeding (friability), and the fornices may become attenuated, resulting in a cervix flush with the vaginal apex. Laboratory assessment is not necessary to diagnose genitourinary syndrome of menopause. If assessed, vaginal $\mathrm{pH}$ is characteristically greater than 5.0 and microscopic wet prep may reveal more white blood cells than epithelial cells, immature epithelial cells (large nuclei) and reduced or absent lactobacilli. ${ }^{73}$ Performed in a clinical laboratory, the vaginal maturation index assesses vaginal estrogen status by evaluating a vaginal smear for percentage of superficial parabasal cells. Estrogen-deprived vaginal epithelium will shed a higher proportion of parabasal cells. ${ }^{2}$

\section{Nonhormonal Treatment of Genitourinary Syndrome of Menopause}

Many women may report having few, if any, symptoms of genitourinary syndrome or may choose to not treat their symptoms. However, when this condition is identified, clinicians should advise women that without active management, it often worsens over time. In women without severe symptoms, recommending use of over-the-counter water-based or siliconebased vaginal lubricants for sexual activity and regular use of long-acting vaginal moisturizers are appropriate. Use of vaginal lubricants reduces friction-related discomfort that women with genitourinary syndrome of menopause experience during sexual activity. Oil-based lubricants should not be used with latex condoms. Consistent use of long-acting vaginal moisturizers can reduce the vaginal $\mathrm{pH}$ to premenopausal levels. ${ }^{73}$ Women with 
genitourinary syndrome of menopause should also be advised that regular sexual activity may help address symptoms and prevent progression. In some women, introital-vaginal contraction or vaginismus may prevent penetration. Use of graduated vaginal dilators, sometimes facilitated by physical therapists specializing in pelvic floor disorders, will often allow such women to resume or initiate comfortable sexual activity. In this setting, initiating low-dose vaginal ET can accelerate progress. ${ }^{73}$

\section{Treating Genitourinary Syndrome of Menopause With Systemic Hormone Therapy}

In general, systemic HT is effective in treating symptoms of genitourinary atrophy. However, $10-15 \%$ of women will experience vulvovaginal symptoms during use of systemic $\mathrm{HT} ; 7^{73}$ such symptoms become more likely when lower than standard doses are used. In this setting, low-dose vaginal estrogen can be added to systemic HT. Alternatively, a woman using oral or transdermal systemic HT can switch to the 3-month systemic vaginal ring (Femring, which releases $0.05 \mathrm{mg} / \mathrm{d}$ or $0.10 \mathrm{mg} /$ day of estradiol) which will address both vasomotor as well as vaginal symptoms. The systemic vaginal estradiol ring (Femring) should not be confused with the 3-month local vaginal ring (Estring), which releases $7.5 \mu$ estradiol/d.

\section{Low-Dose Vaginal Estrogen Therapy in the Treatment of Genitourinary Syndrome of Menopause}

Low-dose vaginal estrogen represents highly effective treatment for symptomatic genitourinary syndrome of menopause. Systematic reviews have noted that tablets, the ring, and creams have comparable efficacy in treating vulvovaginal symptoms. ${ }^{74}$ Vaginal estrogen has also been found to reduce risk of recurrent UTIs and overactive bladder symptoms in menopausal women. The low-dose vaginal estradiol ring is approved to treat urinary urgency and dysuria. In contrast, systemic HT has been noted to increase urinary incontinence. $^{73}$

In the United States, two low-dose estradiol creams, a ring, and a tablet are available. An advantage of the creams is that, in contrast with the ring and tablets, they can be applied not only intravaginally (using graduated plastic applicators supplied with each tube of cream) but also digitally to the vestibular tissues-introitus. However, some women find creams messy.

The estradiol cream includes $0.1 \mathrm{mg}$ active ingredient/g. Package labeling indicates $2-4 \mathrm{~g}$ should initially be applied daily for 1 or 2 weeks; then gradually reduced to one half of initial dosage for a similar period. The recommended maintenance dose is $1 \mathrm{~g}$, one to three times weekly.

The conjugated equine estrogens cream includes $0.625 \mathrm{mg}$ active ingredient per gram. Package labeling indicates 0.5 to $2 \mathrm{~g}$ should be administered cyclically (daily for 21 days then off for 7 days). In practice, during maintenance therapy, most women use vaginal cream 1-3 times weekly on a continuous basis.

The 3-month low-dose estradiol vaginal ring described above releases $7.5 \mu \mathrm{g}$ estradiol/d. An advantage of the ring is the convenience of placement and removal only once every 3 
months. A disadvantage is that some women are not comfortable inserting or removing the ring. Many women and their partners choose to leave the ring in place during intercourse. If the ring is removed, it can be rinsed (avoiding hot water) and replaced as soon as possible.

Vaginal tablets contain $10.3 \mu \mathrm{g}$ estradiol hemihydrate, equivalent to $10 \mu \mathrm{g}$ estradiol. Using a single-use plastic applicator, one tablet is placed intravaginally nightly for 2 weeks, then twice weekly for maintenance therapy. An advantage of the tablets is that women find them less messy than creams; in addition, the applicator is thinner than the cream applicators.

The American College of Obstetricians and Gynecologists and the North American Menopause Society recommend that low-dose vaginal ET may be used as long as needed, including indefinitely, and do not recommend routine use of concomitant progestin therapy for endometrial protection during use of long-term vaginal ET. However, clinicians should recognize that endometrial safety data for currently marketed formulations are based on oneyear trials, with no trials assessing safety of longer-term administration available.. In the absence of reported spotting or bleeding, routine endometrial surveillance during use of vaginal ET is not recommended. ${ }^{23,73}$.

Current package labeling for low-dose vaginal estrogen, as for all systemic HT formulations, includes a boxed warning that refers to endometrial cancer, myocardial infarction, stroke, invasive breast cancer, pulmonary emboli, and dementia. This warning reflects safety concerns associated with findings from clinical trials of systemic HT, including the Women's Health Initiative. In 2014, a group which included members of the North American Menopause Society and the American College of Obstetricians and Gynecologists published an editorial calling for a change in product labeling for low-dose vaginal estrogen, pointing out that the boxed warning is not evidence-based and hurts women by discouraging use of an effective local treatment. The recommendations to change the boxed warning are based on several observations: 1) Blood steroid levels are substantially lower with low-dose vaginal estrogen formulations than those seen with systemic ET; 2) Neither clinical trials nor consistent observational data suggest an elevated risk of the conditions referred to in the boxed warning; and 3) The absence of evidence suggesting that the small changes in blood hormone levels observed during use of these low-dose formulations increase risk for endometrial or breast cancer, venous thromboembolism, coronary artery disease, or cerebrovascular disease. This publication proposes modified-labeling language that would better reflect the safety profile of low-dose vaginal estrogen and potentially enhance safety by focusing on crucial information regarding these formulations that would benefit women and clinicians. ${ }^{75}$ At the time of this article's publication, the FDA is reviewing and considering the proposal.

\section{Ospemifene}

Ospemifene is a systemic estrogen agonist-antagonist that improves genitourinary syndrome of menopause. A one year clinical trial did not identify endometrial safety concerns. However, hot flushes were reported by $7.2 \%$ of participants randomized to ospemifene 60 mg vs. $2.0 \%$ of those randomized to placebo. ${ }^{76}$ In 2013, the FDA approved ospemifene 60 $\mathrm{mg}$ oral tablets for the treatment of dyspareunia in postmenopausal women. 
As with systemic HT and low-dose vaginal ET, package labelling for ospemifene cautions against using this medication in women with a personal history of breast cancer or thromboembolic disease. (Box 1) Published data have not addressed the safety of ospemifene in these patient populations.

\section{Androgens}

Dehydroepiandrosterone, an androgen derivative, is available without a prescription as a dietary supplement. Trials of intravaginal dehydroepiandrosterone have demonstrated effectiveness in treating genitourinary syndrome of menopause. ${ }^{73}$ Clinical trial data addressing the use of vaginal testosterone are limited; longer as well as larger studies are needed to assess efficacy and safety. ${ }^{73}$

\section{USE OF HORMONE THERAPY IN SPECIAL PATIENT POPULATIONS}

\section{Women With Early Menopause}

Women who experience spontaneous or induced menopause (caused by surgery, chemotherapy, or other factors) in their 40s or younger face more severe vasomotor symptoms than women reaching menopause at the mean age (51-52 years), ${ }^{1}$ and are at higher risk for osteoporosis, and possibly coronary heart and neurodegenerative disease. Although little clinical trial data inform management of women with early menopause, use of systemic menopausal HT or oral contraceptives is appropriate in the absence of contraindications. ${ }^{22}$ When systemic HT in used in this patient population, higher than standard doses are often appropriate. ${ }^{77}$

\section{Women With a History of Breast Cancer}

In premenopausal women treated for breast cancer, induced menopause caused by chemotherapy often leads to bothersome vasomotor symptoms. Although observational studies have not found that use of systemic or low-dose vaginal HT increases recurrence risk in breast cancer survivors, this might reflect selection bias in that healthier women with a better baseline prognosis might be more likely to pursue such treatment. ${ }^{78,79}$

In 1997, two clinical trials of HT in women with a history of breast cancer were initiated in Sweden. In the HABITS (hormonal replacement therapy after breast cancer-- is it safe?) $(\mathrm{N}=447)$ and Stockholm $(\mathrm{N}=378)$ studies, ${ }^{80,81}$ the progestin component in most women randomized to estrogen-progestin therapy consisted of continuous norethindrone acetate and cyclical (sequential) medroxyprogesterone, respectively. Because an statistically elevated risk of recurrent breast cancer was noted in the HABITS trial, both studies stopped administering study medications in 2003. At 4 and 10.8 years median follow-up, respectively, no elevated breast cancer-specific or overall mortality was noted in the HABITS or Stockholm studies. Hormone therapy was associated with a persistent elevated risk of recurrence in the HABITS study; in contrast, in the Stockholm study HT was not associated with an elevated recurrence risk at the time study medication was stopped, or at 10.8 years follow-up. ${ }^{80,81}$ Several factors limit the clinical applicability of these two Swedish studies, including that no standardized regimen of HT was employed and that many 
participants concomitantly used tamoxifen and HT, a practice not accepted in the United States.

Given the uncertainty regarding the impact of systemic HT on risk of recurrence, systemic HT in general should not be used in breast cancer survivors; nonhormonal options represent appropriate first-line options for treatment of vasomotor symptoms in this patient population. ${ }^{82}$ Symptomatic breast cancer survivors considering off-label use of systemic HT should be counselled that such therapy may increase recurrence risk. In addition, given the findings from the Women's Health Initiative detailed above, clinicians considering prescribing off-label hormone therapy to treat bothersome menopausal symptoms in breast cancer patients with an intact uterus may consider using estrogen-only therapy (see section on Use of Estrogen-Only Therapy in Women With an Intact Uterus).

Genitourinary syndrome of menopause is prevalent among women with breast cancer, and decisions regarding use of low-dose vaginal estrogen are surrounded with controversy. In contrast with women using systemic HT, in women using the low-dose vaginal ring or tablets, serum estrogen levels remain in the postmenopausal range. Although use of vaginal estrogen cream can increase serum estrogen levels substantially, using very small amounts can improve symptoms without raising serum estrogen levels above those seen in untreated menopausal women. ${ }^{73,75}$

A large observational study found that, in healthy menopausal women, use of low-dose vaginal estrogen was not associated with increased risk of breast cancer. ${ }^{83}$ Likewise, a large observational study of breast cancer survivors found that vaginal estrogen was not associated with an elevated risk of breast cancer recurrence. ${ }^{79}$ Although serum levels of estrogen remain within the normal menopausal range in women using low-dose vaginal estrogen, clinicians and women should be aware that modest increases in serum estrogen levels may occur in this setting. Even such minimal increases may be of concern in women using aromatase inhibitors as adjuvant treatment for breast cancer. Accordingly, clinicians considering prescription of low-dose vaginal estrogen to breast cancer survivors with symptomatic genitourinary syndrome of menopause should make this decision in concert with the patient and her oncologist ${ }^{75,82}$ The safety of ospemifene has not been assessed in breast cancer survivors, and package labeling for this estrogen agonist/antagonist lists known or suspected estrogen-dependent neoplasia as a contraindication.

\section{Carriers of $B R C A 1$ or $B R C A 2$ mutations with no personal history of breast cancer}

As more $B R C A$ mutation carriers are being identified, and more carriers undergo riskreducing salpingo-oophorectomy and bilateral mastectomy, clinicians and mutation carriers more frequently face decisions regarding use of systemic HT. Due to concerns regarding HT and breast cancer, some mutation carriers may delay or avoid salpingo-oophorectomy, a surgery which reduces not only future risk of ovarian cancer but also future risk for breast cancer. ${ }^{84}$

Mutation carriers who have undergone bilateral risk-reducing mastectomy experience a very low baseline future risk for breast cancer. ${ }^{84}$ Accordingly, concerns regarding this disease should not play a major role in decision-making regarding use of systemic HT. 
Among mutation carriers with intact breasts, several studies address risk of breast cancer with use of systemic HT. A 2005 cohort study followed BRCA 1 and 2 carriers with intact breasts, 155 of whom had undergone risk-reducing salpingo-oophorectomy, for a mean follow-up of 3.6 years. Of these women, $60 \%$ and 7\%, respectively, of those who had and had not undergone salpingo-oophorectomy used HT. This study found that bilateral salpingo-oophorectomy reduced future breast cancer risk by some $60 \%$, whether or not women used HT. ${ }^{85}$ In a 2008 case-control study of 472 menopausal BRCA 1 carriers, half had been diagnosed with breast cancer (cases) and the other half (controls) had not received this diagnosis. Prior use of HT was associated with a $43 \%$ reduction in risk of breast cancer. ${ }^{86}$ Finally, a 2011 presentation described a cohort study in which 1,299 BRCA 1 and 2 carriers with intact breasts who had undergone salpingo-oophorectomy were followed for a mean of 5.4 years postoperatively. Overall, use of HT was not associated with an increased risk of breast cancer. Among women with BRCA 1 mutations, use of systemic HT was associated with a reduced risk of breast cancer. ${ }^{87}$ In aggregate, these studies provide reassurance that short-term use of systemic HT does not increase breast cancer risk in women with $B R C A 1$ or 2 mutations and intact breasts.

\section{Women with a history of venous thromboembolism}

Package labelling lists a history of venous thromboembolism as a contraindication to use of all formulations of systemic HT. However, a French observational study found that in women with a history of venous thromboembolism ( $26 \%$ of whom were known to have a thombophilic condition), oral (but not transdermal) ET increased risk of recurrent thrombotic events. ${ }^{88}$ Although this study provides limited support for the safety of transdermal estrogen in women with a history of venous thromboembolism, it cannot be considered definitive given its small size.

\section{Women with a history of endometriosis}

In women with symptomatic endometriosis who have completed childbearing, hysterectomy with bilateral salpingo-oophorectomy may be performed. Often, such women are in their 40s or younger, and face severe menopausal symptoms. In menopausal women who have undergone surgery for endometriosis and elect hormonal treatment for menopausal symptoms, some authorities recommend progestin-only or combined estrogen-progestin formulations to prevent benign or neoplastic growth of endometriosis implants. The concomitant use of continuous progestin in such patients may be particularly important if endometriosis is symptomatic or large residual volumes of endometriotic tissue remained after surgery. ${ }^{89,90}$

\section{Discussion}

HT represents the most effective treatment for menopausal vasomotor and related symptoms. Among appropriate candidates, estrogen-progestogen combination HT is recommended to treat bothersome symptoms in women with an intact uterus, while estrogen-alone therapy can be used for symptomatic women posthysterectomy. Findings from the Women's Health Initiative and other recent randomized clinical trials have helped to clarify the benefits and risks of combination estrogen-progestin and estrogen-alone 
therapy. Although combination and estrogen-alone therapy was associated with a complex pattern of benefits and risks in both Women's Health Initiative trials, absolute risks tended to be small. Given the lower rates of adverse events on HT among women close to menopause onset and at lower baseline risk of cardiovascular disease, the use of risk stratification and personalized risk assessment represents a sound strategy for optimizing the benefit: risk profile and safety of hormone therapy. Treatment duration should be individualized based on patients' risk profiles and personal preferences. Genitourinary syndrome of menopause represents a common condition that reduces the quality of life of many menopausal women. Low-dose vaginal estrogen is highly effective in treating this condition. Because custom-compounded hormones have not been tested for efficacy or safety, FDA-approved HT is preferred. A low-dose formulation of paroxetine mesylate currently represents the only nonhormonal medication that is FDA-approved to treat vasomotor symptoms. Gynecologists and other clinicians who remain abreast of data addressing the benefit: risk profile of HT as well as nonhormonal treatments can help menopausal women make sound choices regarding management of menopausal symptoms.

\section{Supplementary Material}

Refer to Web version on PubMed Central for supplementary material.

\section{Acknowledgments}

Dr. Kaunitz has served on the advisory boards for Actavis, Bayer, and Teva. His institution receives financial support for clinical trials from Bayer and TherapeuticsMD.

\section{References}

1. Freeman EW, Sammel MD, Sanders RJ. Risk of long-term hot flashes after natural menopause: evidence from the Penn Ovarian Aging Study cohort. Menopause. 2014; 21:924-932. [PubMed: 24473530]

2. North American Menopause Society, Menopause Practice: A Clinician's Guide. 5th Ed.. 2014.

3. Nelson HD. Menopause (Seminar). Lancet. 2008; 371:760-770. [PubMed: 18313505]

4. Freedman RR. Physiology of hot flashes. American journal of human biology : the official journal of the Human Biology Council. 2001; 13:453-464. [PubMed: 11400216]

5. Casper RF, Yen SS. Neuroendocrinology of menopausal flushes: an hypothesis of flush mechanism. Clinical endocrinology. 1985; 22:293-312. [PubMed: 3884189]

6. Freedman RR, Krell W. Reduced thermoregulatory null zone in postmenopausal women with hot flashes. American journal of obstetrics and gynecology. 1999; 181:66-70. [PubMed: 10411797]

7. Gold EB, Colvin A, Avis N, Bromberger J, Greendale GA, Powell L, et al. Longitudinal analysis of the association between vasomotor symptoms and race/ethnicity across the menopausal transition: study of women's health across the nation. American journal of public health. 2006; 96:1226-1235. [PubMed: 16735636]

8. Sievert LL. Menopause across cultures: clinical considerations. Menopause. 2014; 21:421-423. [PubMed: 24149928]

9. Brown DE, Sievert LL, Morrison LA, Reza AM, Mills PS. Do Japanese American women really have fewer hot flashes than European Americans? The Hilo Women's Health Study. Menopause. 2009; 16:870-876. [PubMed: 19367185]

10. Freeman EW, Sammel MD, Lin H, Liu Z, Gracia CR. Duration of menopausal hot flushes and associated risk factors. Obstetrics and gynecology. 2011; 117:1095-1104. [PubMed: 21508748] 
11. Pinkerton JV, Wilson CS. Perspectives on the first randomized sham-controlled trial of stellate ganglion block for hot flashes. Menopause. 2014; 21:788-791. [PubMed: 24983275]

12. Elkins GR, Fisher WI, Johnson AK, Carpenter JS, Keith TZ. Clinical hypnosis in the treatment of postmenopausal hot flashes: a randomized controlled trial. Menopause. 2013; 20:291-298. [PubMed: 23435026]

13. Dodin S, Blanchet C, Marc I, Ernst E, Wu T, Vaillancourt C, et al. Acupuncture for menopausal hot flushes. The Cochrane database of systematic reviews. 2013; 7:CD007410. [PubMed: 23897589]

14. Moilanen JM, Mikkola TS, Raitanen JA, Heinonen RH, Tomas EI, Nygard CH, et al. Effect of aerobic training on menopausal symptoms--a randomized controlled trial. Menopause. 2012; 19:691-696. [PubMed: 22334056]

15. Sternfeld B, Guthrie KA, Ensrud KE, LaCroix AZ, Larson JC, Dunn AL, et al. Efficacy of exercise for menopausal symptoms: a randomized controlled trial. Menopause. 2014; 21:330-338. [PubMed: 23899828]

16. Carpenter JS, Burns DS, Wu J, Otte JL, Schneider B, Ryker K, et al. Paced respiration for vasomotor and other menopausal symptoms: a randomized, controlled trial. Journal of general internal medicine. 2013; 28:193-200. [PubMed: 22936289]

17. Saensak S, Vutyavanich T, Somboonporn W, Srisurapanont M. Effectiveness of a modified version of the applied relaxation technique in treatment of perimenopausal and postmenopausal symptoms. International journal of women's health. 2013; 5:765-771.

18. Carmody JF, Crawford S, Salmoirago-Blotcher E, Leung K, Churchill L, Olendzki N. Mindfulness training for coping with hot flashes: results of a randomized trial. Menopause. 2011; 18:611-620. [PubMed: 21372745]

19. Newton KM, Reed SD, LaCroix AZ, Grothaus LC, Ehrlich K, Guiltinan J. Treatment of vasomotor symptoms of menopause with black cohosh, multibotanicals, soy, hormone therapy, or placebo: a randomized trial. Annals of internal medicine. 2006; 145:869-879. [PubMed: 17179056]

20. Lethaby A, Marjoribanks J, Kronenberg F, Roberts H, Eden J, Brown J. Phytoestrogens for menopausal vasomotor symptoms. The Cochrane database of systematic reviews. 2013; 12:CD001395. [PubMed: 24323914]

21. Cohen LS, Joffe H, Guthrie KA, Ensrud KE, Freeman M, Carpenter JS, et al. Efficacy of omega-3 for vasomotor symptoms treatment: a randomized controlled trial. Menopause. 2014; 21:347-354. [PubMed: 23982113]

22. North American Menopause S. The 2012 hormone therapy position statement of: The North American Menopause Society. Menopause. 2012; 19:257-271. [PubMed: 22367731]

23. American College of Obstetricians Gynecologists, ACOG Practice Bulletin No. 141: management of menopausal symptoms. Obstetrics and gynecology. 2014; 123:202-216. [PubMed: 24463691]

24. Grady D, Gebretsadik T, Kerlikowske K, Ernster V, Petitti D. Hormone replacement therapy and endometrial cancer risk: a meta-analysis. Obstetrics and gynecology. 1995; 85:304-313. [PubMed: 7824251]

25. Anderson GL, Judd HL, Kaunitz AM, Barad DH, Beresford SA, Pettinger M, et al. Effects of estrogen plus progestin on gynecologic cancers and associated diagnostic procedures: the Women's Health Initiative randomized trial. Jama. 2003; 290:1739-1748. [PubMed: 14519708]

26. Manson JE, Chlebowski RT, Stefanick ML, Aragaki AK, Rossouw JE, Prentice RL, et al. Menopausal hormone therapy and health outcomes during the intervention and extended poststopping phases of the Women's Health Initiative randomized trials. Jama. 2013; 310:13531368. [PubMed: 24084921]

27. Jaakkola S, Lyytinen H, Pukkala E, Ylikorkala O. Endometrial cancer in postmenopausal women using estradiol-progestin therapy. Obstetrics and gynecology. 2009; 114:1197-1204. [PubMed: 19935019]

28. Schiff I, Tulchinsky D, Cramer D, Ryan KJ. Oral medroxyprogesterone in the treatment of postmenopausal symptoms. Jama. 1980; 244:1443-1445. [PubMed: 6775094]

29. Maclennan AH, Broadbent JL, Lester S, Moore V. Oral oestrogen and combined oestrogen/ progestogen therapy versus placebo for hot flushes. The Cochrane database of systematic reviews. 2004:CD002978. [PubMed: 15495039] 
30. Pinkerton JV, Harvey JA, Lindsay R, Pan K, Chines AA, Mirkin S, et al. Effects of bazedoxifene/ conjugated estrogens on the endometrium and bone: a randomized trial. The Journal of clinical endocrinology and metabolism. 2014; 99:E189-E198. [PubMed: 24438370]

31. Pinkerton JV, Harvey JA, Pan K, Thompson JR, Ryan KA, Chines AA, et al. Breast effects of bazedoxifene-conjugated estrogens: a randomized controlled trial. Obstetrics and gynecology. 2013; 121:959-968. [PubMed: 23635731]

32. Kaunitz AM. Transdermal and vaginal estradiol for the treatment of menopausal symptoms: the nuts and bolts. Menopause. 2012; 19:602-603. [PubMed: 22549171]

33. Santoro NSS. Glob.libr.women's med. (ISSN: 1756-228). 2012

34. Depypere H, Inki P. The levonorgestrel-releasing intrauterine system for endometrial protection during estrogen replacement therapy: a clinical review. Climacteric : the journal of the International Menopause Society. 2015:1-13.

35. Chen WY, Rosner B, Hankinson SE, Colditz GA, Willett WC. Moderate alcohol consumption during adult life, drinking patterns, and breast cancer risk. Jama. 2011; 306:1884-1890. [PubMed: 22045766]

36. Mendelsohn ME, Karas RH. Molecular and cellular basis of cardiovascular gender differences. Science. 2005; 308:1583-1587. [PubMed: 15947175]

37. Writing Group on behalf of Workshop Consensus G. Aging, menopause, cardiovascular disease and HRT. International Menopause Society Consensus Statement. Climacteric : the journal of the International Menopause Society. 2009; 12:368-377. [PubMed: 19811229]

38. Santen RJ, Allred DC, Ardoin SP, Archer DF, Boyd N, Braunstein GD, et al. Postmenopausal hormone therapy: an Endocrine Society scientific statement. The Journal of clinical endocrinology and metabolism. 2010; 95:s1-s66. [PubMed: 20566620]

39. Mikkola TS, Clarkson TB. Estrogen replacement therapy, atherosclerosis, and vascular function. Cardiovascular research. 2002; 53:605-619. [PubMed: 11861031]

40. Bray PF, Larson JC, Lacroix AZ, Manson J, Limacher MC, Rossouw JE, et al. Usefulness of baseline lipids and $\mathrm{C}$-reactive protein in women receiving menopausal hormone therapy as predictors of treatment-related coronary events. The American journal of cardiology. 2008; 101:1599-1605. [PubMed: 18489937]

41. Wild RA, Wu C, Curb JD, Martin LW, Phillips L, Stefanick M, et al. Coronary heart disease events in the Women's Health Initiative hormone trials: effect modification by metabolic syndrome: a nested case-control study within the Women's Health Initiative randomized clinical trials. Menopause. 2013; 20:254-260. [PubMed: 23435021]

42. Manson JE. The role of personalized medicine in identifying appropriate candidates for menopausal estrogen therapy. Metabolism: clinical and experimental. 2013; 62(Suppl 1):S15-S19. [PubMed: 23018143]

43. Bassuk SS, Manson JE. Menopausal hormone therapy and cardiovascular disease risk: utility of biomarkers and clinical factors for risk stratification. Clinical chemistry. 2014; 60:68-77. [PubMed: 24379312]

44. Schierbeck LL, Rejnmark L, Tofteng CL, Stilgren L, Eiken P, Mosekilde L, et al. Effect of hormone replacement therapy on cardiovascular events in recently postmenopausal women randomised trial. Bmj. 2012; 345:e6409. [PubMed: 23048011]

45. Hodis HNMW, Shoupe D, Azen SP, Stanczyk FZ, Hwang-Levine J, Budoff MJ, Henderson VW. Testing the menopausal hormone therapy timing hypothesis: the Early versus Late Intervention Trial with Estradiol. Circulation. 2014

46. Rossouw J, Manson JE, Kaunitz AM, Stefanick ML. Study had insufficient power to investigate safety. Letter. Bmj. 2012; 345:e8146. [PubMed: 23208257]

47. Harman SM, Black DM, Naftolin F, Brinton EA, Budoff MJ, Cedars MI, et al. Arterial imaging outcomes and cardiovascular risk factors in recently menopausal women: a randomized trial. Annals of internal medicine. 2014; 161:249-260. [PubMed: 25069991]

48. Manson JE, Ames JM, Shapiro M, Gass ML, Shifren JL, Stuenkel CA, et al. Algorithm and mobile app for menopausal symptom management and hormonal/non-hormonal therapy decision making: a clinical decision-support tool from The North American Menopause Society. Menopause. 2014; 22:247-253. [PubMed: 25314150] 
49. Goff DC Jr, Lloyd-Jones DM, Bennett G, Coady S, D"Agostino RB, Gibbons R, et al. 2013 ACC/AHA guideline on the assessment of cardiovascular risk: a report of the American College of Cardiology/American Heart Association Task Force on Practice Guidelines. Circulation. 2014; 129:S49-S73. [PubMed: 24222018]

50. Sarrel PM, Njike VY, Vinante V, Katz DL. The mortality toll of estrogen avoidance: an analysis of excess deaths among hysterectomized women aged 50 to 59 years. American journal of public health. 2013; 103:1583-1588. [PubMed: 23865654]

51. American Geriatrics Society Beers Criteria Update Expert P. American Geriatrics Society updated Beers Criteria for potentially inappropriate medication use in older adults. Journal of the American Geriatrics Society. 2012; 60:616-631. [PubMed: 22376048]

52. American College of Obstetricians Gynecologists, ACOG Committee Opinion No. 556: Postmenopausal estrogen therapy: route of administration and risk of venous thromboembolism. Obstetrics and gynecology. 2013; 121:887-890. [PubMed: 23635705]

53. Rott H. Prevention and treatment of venous thromboembolism during HRT: current perspectives. International journal of general medicine. 2014; 7:433-440. [PubMed: 25210472]

54. Kaunitz AM. Extended duration use of menopausal hormone therapy. Menopause. 2014; $21: 679$ 681. [PubMed: 24398408]

55. Pinkerton JV, Santoro N. Compounded bioidentical hormone therapy: identifying use trends and knowledge gaps among US women. Menopause. 2015

56. Kaunitz AM, Kaunit JD. Compounded bioidentical hormone therapy: time for a reality check? Menopause. 2015 published ahead of print.

57. Pinkerton JV. What are the concerns about custom-compounded "bioidentical" hormone therapy? Menopause. 2014; 21:1298-1300. [PubMed: 25387347]

58. Timmer CJ, Geurts TB. Bioequivalence assessment of three different estradiol formulations in postmenopausal women in an open, randomized, single-dose, 3-way cross-over study. European journal of drug metabolism and pharmacokinetics. 1999; 24:47-53. [PubMed: 10412891]

59. Cherry N, McNamee R, Heagerty A, Kitchener H, Hannaford P. Long-term safety of unopposed estrogen used by women surviving myocardial infarction: 14-year follow-up of the ESPRIT randomised controlled trial. BJOG : an international journal of obstetrics and gynaecology. 2014; 121:700-7055. discussion 5. [PubMed: 24533510]

60. Effects of hormone replacement therapy on endometrial histology in postmenopausal women. The Postmenopausal Estrogen/Progestin Interventions (PEPI) Trial. The Writing Group for the PEPI Trial. Jama. 1996; 275:370-375. [PubMed: 8569016]

61. Steiner AZ, Xiang M, Mack WJ, Shoupe D, Felix JC, Lobo RA, et al. Unopposed estradiol therapy in postmenopausal women: results from two randomized trials. Obstetrics and gynecology. 2007; 109:581-587. [PubMed: 17329508]

62. Dood RL, Gracia CR, Sammel MD, Haynes K, Senapati S, Strom BL. Endometrial cancer after endometrial ablation vs medical management of abnormal uterine bleeding. Journal of minimally invasive gynecology. 2014; 21:744-752. [PubMed: 24590007]

63. Somboonporn W, Davis S, Seif MW, Bell R. Testosterone for peri- and postmenopausal women. The Cochrane database of systematic reviews. 2005:CD004509. [PubMed: 16235365]

64. Kingsberg SA, Woodard T. Female sexual dysfunction: focus on low desire. Obstetrics and gynecology. 2015; 125:477-486. [PubMed: 25569014]

65. Huang G, Basaria S, Travison TG, Ho MH, Davda M, Mazer NA, et al. Testosterone doseresponse relationships in hysterectomized women with or without oophorectomy: effects on sexual function, body composition, muscle performance and physical function in a randomized trial. Menopause. 2014; 21:612-623. [PubMed: 24281237]

66. Sideras K, Loprinzi CL. Nonhormonal management of hot flashes for women on risk reduction therapy. Journal of the National Comprehensive Cancer Network : JNCCN. 2010; 8:1171-1179. [PubMed: 20971841]

67. Simon JA, Portman DJ, Kaunitz AM, Mekonnen H, Kazempour K, Bhaskar S, et al. Low-dose paroxetine $7.5 \mathrm{mg}$ for menopausal vasomotor symptoms: two randomized controlled trials. Menopause. 2013; 20:1027-1035. [PubMed: 24045678] 
68. Joffe H, Guthrie KA, LaCroix AZ, Reed SD, Ensrud KE, Manson JE, et al. Low-dose estradiol and the serotonin-norepinephrine reuptake inhibitor venlafaxine for vasomotor symptoms: a randomized clinical trial. JAMA internal medicine. 2014; 174:1058-1066. [PubMed: 24861828]

69. Walega DR, Rubin LH, Banuvar S, Shulman LP, Maki PM. Effects of stellate ganglion block on vasomotor symptoms: findings from a randomized controlled clinical trial in postmenopausal women. Menopause. 2014; 21:807-814. [PubMed: 24496086]

70. Jewett PI, Gangnon RE, Trentham-Dietz A, Sprague BL. Trends of postmenopausal estrogen plus progestin prevalence in the United States between 1970 and 2010. Obstetrics and gynecology. 2014; 124:727-733. [PubMed: 25198271]

71. Lindau ST, Schumm LP, Laumann EO, Levinson W, O'Muircheartaigh CA, Waite LJ. A study of sexuality and health among older adults in the United States. The New England journal of medicine. 2007; 357:762-774. [PubMed: 17715410]

72. Portman DJ, Gass ML. Vulvovaginal Atrophy Terminology Consensus Conference P. Genitourinary syndrome of menopause: new terminology for vulvovaginal atrophy from the International Society for the Study of Women's Sexual Health and the North American Menopause Society. Menopause. 2014; 21:1063-1068. [PubMed: 25160739]

73. Management of symptomatic vulvovaginal atrophy: 2013 position statement of The North American Menopause Society. Menopause. 2013; 20:888-902. quiz 3-4. [PubMed: 23985562]

74. Rahn DD, Carberry C, Sanses TV, Mamik MM, Ward RM, Meriwether KV, et al. Vaginal estrogen for genitourinary syndrome of menopause: a systematic review. Obstetrics and gynecology. 2014; 124:1147-1156. [PubMed: 25415166]

75. Manson JE, Goldstein SR, Kagan R, Kaunitz AM, Liu JH, Pinkerton JV, et al. Why the product labeling for low-dose vaginal estrogen should be changed. Menopause. 2014; 21:911-916. [PubMed: 25140698]

76. Simon JA, Lin VH, Radovich C, Bachmann GA. Ospemifene Study G. One-year long-term safety extension study of ospemifene for the treatment of vulvar and vaginal atrophy in postmenopausal women with a uterus. Menopause. 2013; 20:418-427. [PubMed: 23096251]

77. Rebar RW. Premature ovarian failure. Obstetrics and gynecology. 2009; 113:1355-1363. [PubMed: 19461434]

78. Col NF, Hirota LK, Orr RK, Erban JK, Wong JB, Lau J. Hormone replacement therapy after breast cancer: a systematic review and quantitative assessment of risk. Journal of clinical oncology : official journal of the American Society of Clinical Oncology. 2001; 19:2357-2363. [PubMed: 11304788]

79. O"Meara ES, Rossing MA, Daling JR, Elmore JG, Barlow WE, Weiss NS. Hormone replacement therapy after a diagnosis of breast cancer in relation to recurrence and mortality. Journal of the National Cancer Institute. 2001; 93:754-762. [PubMed: 11353785]

80. Holmberg L, Iversen OE, Rudenstam CM, Hammar M, Kumpulainen E, Jaskiewicz J, et al. Increased risk of recurrence after hormone replacement therapy in breast cancer survivors. Journal of the National Cancer Institute. 2008; 100:475-482. [PubMed: 18364505]

81. von Schoultz E, Rutqvist LE. Stockholm Breast Cancer Study G. Menopausal hormone therapy after breast cancer: the Stockholm randomized trial. Journal of the National Cancer Institute. 2005; 97:533-535. [PubMed: 15812079]

82. American College of Obstetricians Gynecologists, ACOG Practice Bulletin No. 126: Management of gynecologic issues in women with breast cancer. Obstetrics and gynecology. 2012; 119:666682. [PubMed: 22353976]

83. Lyytinen H, Pukkala E, Ylikorkala O. Breast cancer risk in postmenopausal women using estrogen-only therapy. Obstetrics and gynecology. 2006; 108:1354-1360. [PubMed: 17138766]

84. Finch AP, Lubinski J, Moller P, Singer CF, Karlan B, Senter L, et al. Impact of oophorectomy on cancer incidence and mortality in women with a BRCA1 or BRCA2 mutation. Journal of clinical oncology : official journal of the American Society of Clinical Oncology. 2014; 32:1547-1553. [PubMed: 24567435]

85. Rebbeck TR, Friebel T, Wagner T, Lynch HT, Garber JE, Daly MB, et al. Effect of short-term hormone replacement therapy on breast cancer risk reduction after bilateral prophylactic oophorectomy in BRCA1 and BRCA2 mutation carriers: the PROSE Study Group. Journal of 
clinical oncology : official journal of the American Society of Clinical Oncology. 2005; 23:78047810. [PubMed: 16219936]

86. Eisen A, Lubinski J, Gronwald J, Moller P, Lynch HT, Klijn J, et al. Hormone therapy and the risk of breast cancer in BRCA1 mutation carriers. Journal of the National Cancer Institute. 2008; 100:1361-1367. [PubMed: 18812548]

87. Domchek SM, Mitchell G, Lindeman GJ, Tung NM, Balmana J, Isakoff SJ, et al. Challenges to the development of new agents for molecularly defined patient subsets: lessons from BRCA1/2associated breast cancer. Journal of clinical oncology : official journal of the American Society of Clinical Oncology. 2011; 29:4224-4226. [PubMed: 21931031]

88. Olie V, Plu-Bureau G, Conard J, Horellou MH, Canonico M, Scarabin PY. Hormone therapy and recurrence of venous thromboembolism among postmenopausal women. Menopause. 2011; 18:488-493. [PubMed: 21178641]

89. Giudice LC. Clinical practice. Endometriosis. The New England journal of medicine. 2010; 362:2389-2398. [PubMed: 20573927]

90. The Society of Obstricians and Gynaecologists of Canada. Managing Menopause. Journal of Obstetrics and Gynaecology Canada. 2014; 36:S1-S80. 


\section{Box 1}

\section{Menopausal Hormone Therapy/Related Medications: Indications and Contraindications*}

\section{Systemic Estrogen Therapy (oral, transdermal, and high-dose vaginal formulations)}

- Indications: management of moderate-to-severe vasomotor symptoms (Prevention of osteoporosis among women at high risk of osteoporotic fracture who are unable to tolerate standard preventive medications)

- Contraindications:

Absolute: unexplained vaginal bleeding; liver dysfunction or disease; history of deep venous thrombosis or pulmonary embolism; known blood clotting disorder or thrombophilia (transdermal may be an option in some women at elevated risk for venous thrombosis); untreated hypertension; history of breast, endometrial cancer, or other estrogen-dependent neoplasia; known hypersensitivity to hormone therapy, or history of CHD, stroke, or TIA. Concomitant progestational therapy should be prescribed when a uterus is present.

Relative: high triglycerides ( $>400 \mathrm{mg} / \mathrm{dL}, 4.5 \mathrm{mmol} / \mathrm{L}$ ) or gallbladder disease (oral estrogen should be avoided but transdermal estrogen may be an option); elevated risk of breast cancer (5-year breast cancer risk $>5 \%$ by NCI or IBIS assessment BC: see http://www.cancer.gov/bcrisktool/).

\section{CE/bazedoxifene}

- Indications: same indications as above: an additional FDA-approved option for women with concerns about breast tenderness, breast density, or uterine bleeding with conventional therapy.

- Contraindications:

Absolute and relative: Same as above.

\section{Low-Dose Vaginal Estrogen}

- Indications: treatment of genitourinary symptoms of menopause, including vaginal dryness and dyspareunia.

- Contraindications (absolute): unexplained vaginal bleeding; known or suspected breast cancer or endometrial cancer, or other estrogen-dependent neoplasia. For some women with a personal history of breast cancer, use might be considered after consultation with the patient's oncologist; however, particular caution is appropriate among women taking aromatase inhibitors. Although concomitant progestational therapy is not recommended, endometrial evaluation should be performed if any vaginal spotting or bleeding occurs.

\section{Ospemifene}

- Indications: Treatment of genitourinary symptoms of menopause, including vaginal dryness and dyspareunia, among women preferring an oral treatment. 
- Contraindications (absolute): same as for low-dose vaginal estrogen. Also should not be used in patients with past or current venous or arterial thromboembolic disease, severe liver disease, or those using estrogens or estrogen agonists/antagonists.

*See product labeling for more comprehensive listing. $\mathrm{CHD}=$ coronary heart disease; TIA $=$ transient ischemic attack; FDA = U.S. Food and Drug Administration; NCI = National Cancer Institute; IBIS = International Breast Cancer Intervention Study. 


\section{Box 2}

Medical and latrogenic Conditions That Can Masquerade as Hot Flushes

Anxiety disorders

Autoimmune disorders

Carcinoid syndromes

Diabetic autonomic dysfunction/hypoglycemia

Epilepsy

Infection

$\underline{\text { Insulinoma/pancreatic tumors }}$

Leukemia/lymphoma mast-cell disorders

New-onset hypertension

Thyroid disease

Tuberculosis

Use of selective-reuptake inhibitors or serotonin norepinephrine-reuptake inhibitors

Data from North American Menopause Society. Menopause practice: a clinician's guide. $5^{\text {th }}$ ed. Mayfield Heights (OH): North American Menopause Society; 2014. 
Age $50-59$

CEE+MPA Trial

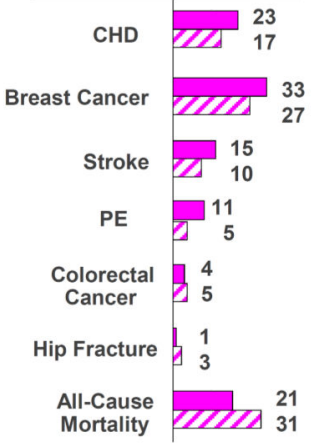

\section{CEE-Alone Trial}

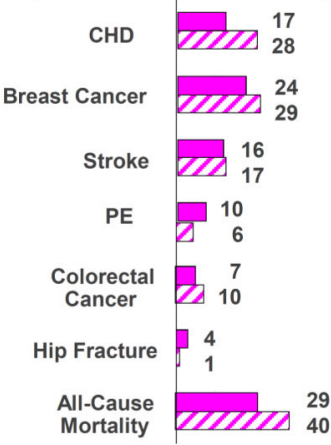

Age 60-69

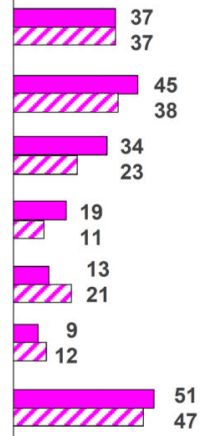

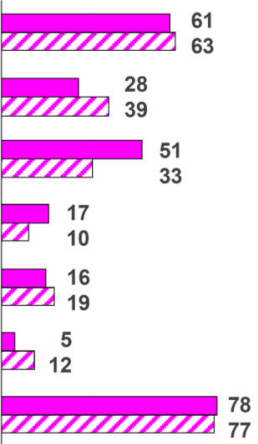

Age $70-79$

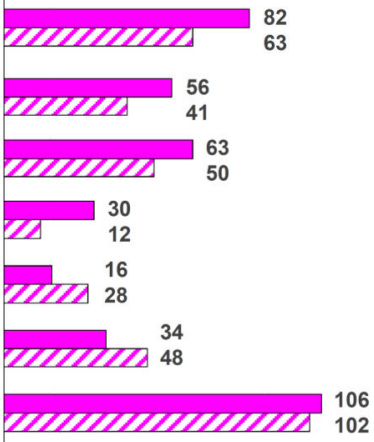

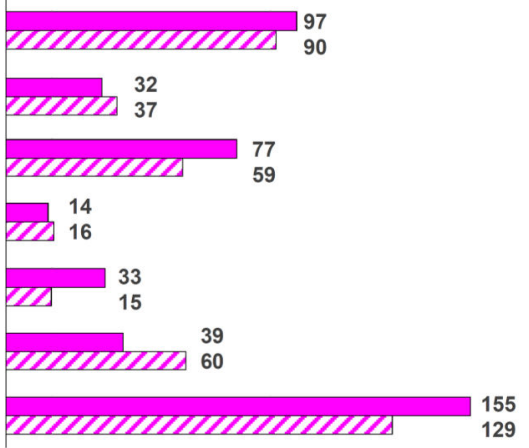

Adapted from Manson JE, Chlebowski RT, Stefanick ML, et al. JAMA 2013. (Reference 26)

Figure 1.

Women's Health Initiative hormone therapy trials: Absolute risks (cases per 10,000 personyears) for outcomes in the intervention phases of the estrogen-progestin and estrogen-alone trials, by age group. $\mathrm{CEE}=$ conjugated equine estrogens; $\mathrm{MPA}=$ medroxyprogesterone acetate.

Modified from Manson JE, Chlebowski RT, Stefanick ML, Aragaki AK, Rossouw JE, Prentice RL, et al. Menopausal hormone therapy and health outcomes during the intervention and extended poststopping phases of the Women's Health Initiative randomized trials. JAMA 2013 310:1353-68. 


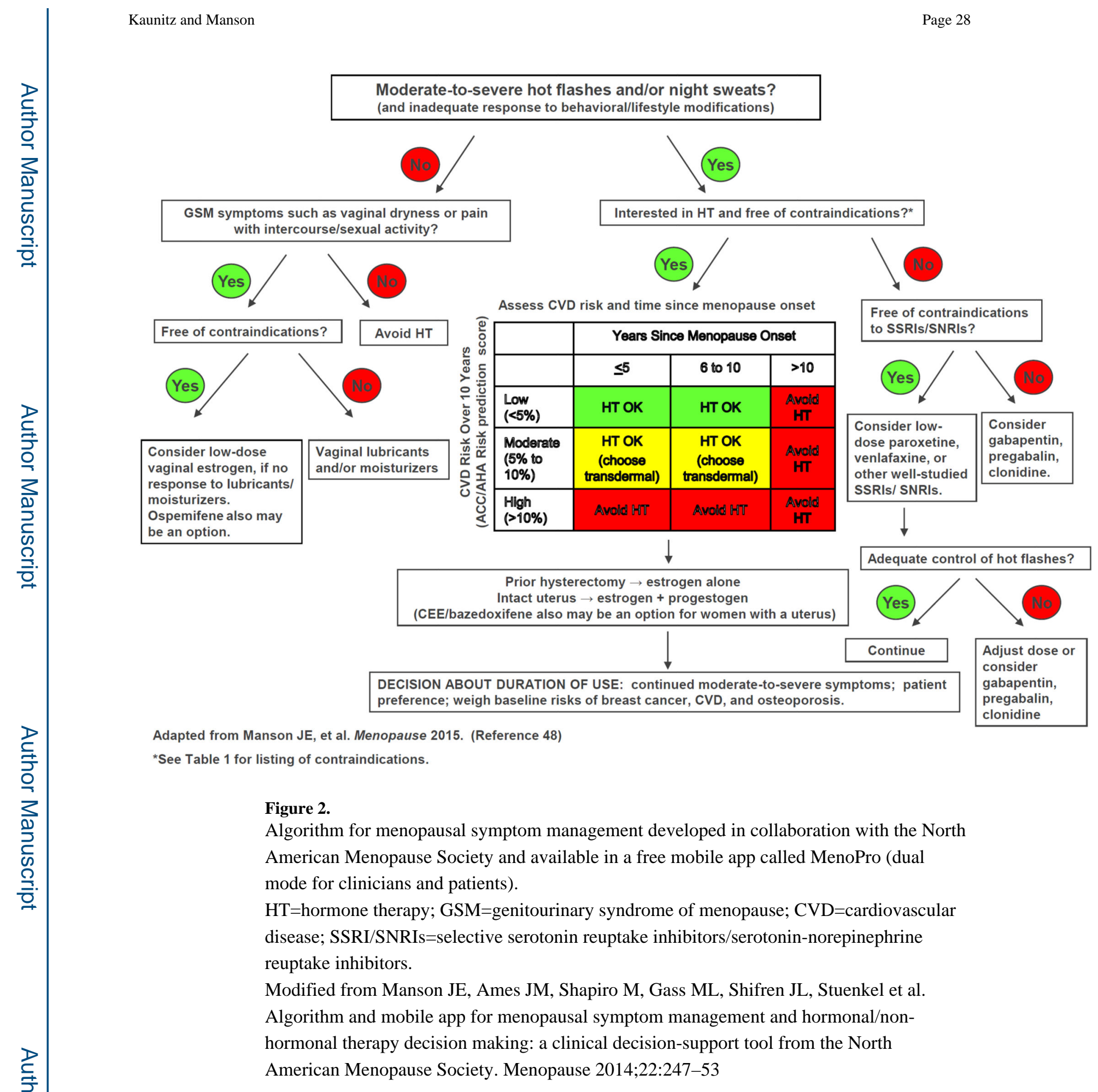

Obstet Gynecol. Author manuscript; available in PMC 2016 October 01. 
Table 1

Health Outcomes (Hazard Ratios [95\% Confidence Intervals]) of Menopausal Hormone Therapy in the Women's Health Initiative Trials*

\begin{tabular}{|c|c|c|c|c|}
\hline \multirow[b]{2}{*}{ Outcome } & \multicolumn{4}{|c|}{ Conjugated Equine Estrogen $(0.625 \mathrm{mg} / \mathrm{d})$ Plus Medroxyprogesterone Acetate $(2.5 \mathrm{mg} / \mathrm{d})$} \\
\hline & Intervention ${ }^{\dagger}$ & $P$ & Cumulative Follow-up & $P$ \\
\hline \multicolumn{5}{|l|}{ Cardiovascular disease } \\
\hline Coronary heart disease & $1.18(0.95-1.45)$ & .13 & $1.09(0.96-1.24)$ & .19 \\
\hline Stroke & $1.37(1.07-1.76)$ & .01 & $1.16(1.00-1.35)$ & .06 \\
\hline $\begin{array}{l}\text { Coronary artery' bypass } \\
\text { graft or percutaneous } \\
\text { coronary intervention }\end{array}$ & $0.95(0.78-1.16)$ & .64 & $1.04(0.92-1.18)$ & .50 \\
\hline Deep vein thrombosis & $1.87(1.37-2.54)$ & $<.001$ & $1.24(1.01-1.53)$ & .04 \\
\hline Pulmonary' embolism & $1.98(1.36-2.87)$ & $<.001$ & $1.26(1.11-1.48)$ & $<.001$ \\
\hline Cardiovascular deaths & $1.05(0.76-1.45)$ & .77 & $0.97(0.83-1.14)$ & .73 \\
\hline \multicolumn{5}{|l|}{ Cancer } \\
\hline Invasive breast cancer & $1.24(1.01-1.53)$ & .04 & $1.28(1.11-1.48)$ & $<.001$ \\
\hline Colorectal cancer & $0.62(0.43-0.89)$ & .009 & $0.80(0.63-1.01)$ & .06 \\
\hline Endometrial cancer & $0.83(0.49-1.40)$ & .49 & $0.67(0.49-0.91)$ & .01 \\
\hline All cancer types// & $1.02(0.91-1.15)$ & .69 & $1.04(0.96-1.12)$ & 33 \\
\hline \multicolumn{5}{|l|}{ Other endpoints } \\
\hline Hip fracture & $0.67(0.47-0.95)$ & .03 & $0.81(0.68-0.97)$ & .02 \\
\hline All-cause mortality & $0.97(0.81-1.16)$ & 76 & $0.99(0.91-1.08)$ & 0.87 \\
\hline Vasomotor symptoms ${ }^{I I}$ & $0.36(0.27-0.49)$ & $<.001$ & NR & \\
\hline Diabetes $\#$ & $0.81(0.70-0.94)$ & .005 & $1.02(0.93-1.12)$ & .66 \\
\hline Gallbladder disease & $1.57(1.36-1.80)$ & $<.001$ & NR & \\
\hline Global index ${ }^{* *}$ & $1.12(1.02-1.24)$ & .02 & $1.06(1.00-1.13)$ & .05 \\
\hline
\end{tabular}

NA, not applicable; NR, not reported.

* Data from Manson Jb, Chlebowski KT, Stefanick Mt, Aragaki AK, Kossouw Jt, Prentice Kt, et al. Menopausal hormone therapy and health outcomes during the intervention and extended poststopping phases of the Women's Health Initiative randomized trials. JAMA 2013;310:1353-68.

${ }^{\dagger}$ Median follow-up was 5.6 years.

\$ Median follow-up was 13.0 years.

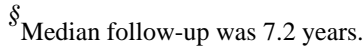

/Excludes nonmelanoma skin cancer.

${ }^{I l}$ In symptomatic women aged $50-54$ years.

\# Self-reported in women who did not report the condition at baseline.

$* *$

The global index of risks and benefits includes the primary endpointsof coronary heart disease and invasive breast cancer plus other outcomes including stroke, pulmonary embolism, endometrial cancer (for conjugated equine estrogen plus medroxyprogesterone acetate group), colorectal cancer, hip fracture, and all-cause mortality. 